\title{
Auf der Spur
}

\section{Erhard Taverna}

Dr. med., Mitglied der Redaktion

Drei ältere Kollegen, die nicht selbstgefällig zur Ruhe kommen. Drei reife Alterswerke, die sich mit unserer Existenz auseinandersetzen. René Bloch treibt die Frage um, was von Nöten wäre, um die selbstzerstörerischen Allmachtsfantasien der Menschen zu überwinden. Albert Mambourg verfolgt die Traumpfade einer letztlich universalen, unerfüllbaren Sehnsucht. Sergio Marengos Poesie besingt dreisprachig die Schönheit und Tragik unseres Daseins, wofür er kürzlich in Genua von der Associazione Medici Scrittori Italiani geehrt wurde.

\section{Destruktionstrieb und Transzendenz}

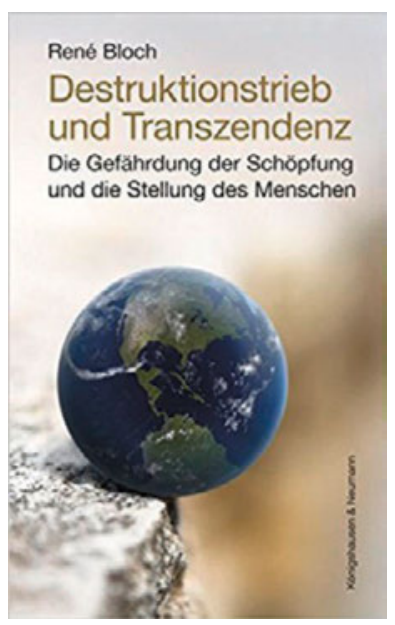

René Bloch

\section{Destruktionstrieb und Transzendenz}

Würzburg: Königshausen \& Neumann; 2017.

130 Seiten. 21.90 CHF.

ISBN 978-3-8260-6171-4

Unter Transzendenz versteht der Psychiater René Bloch die Erkenntnis kosmischer Zyklen von Geburt und Vergänglichkeit als Matrix von allem Lebendigen

\section{Der Mensch soll seine Grössenfantasien und seine moralische Unreife überwinden.}

auf diesem Planeten. Nur wenn sich der Mensch seine unüberwindbare Abhängigkeit von dieser Natur eingesteht, kann er die nötigen Gegenkräfte zu seiner Selbst- zerstörung entwickeln. Für dieses globale Erwachen brauche es ein neues Paradigma einer konstruktiven Form von Selbstnegation. Eine geistig-moralische

\section{Es gibt nur die Fragmente durcheinander-} wirbelnder Zeiten.

Umorientierung, eine maximale geistige Konzentration und Wachsamkeit, um sich selbst in voller Interaktion mit der Umwelt zu erkennen. Der Mensch soll seine Grössenfantasien und seine moralische Unreife überwinden, um in der erkannten und akzeptierten Abhängigkeit neue Freiheitsgrade zu finden. Auf den Spuren aktueller Katastrophen, die der Autor wortreich vor Augen führt, liest sich das Buch als Plädoyer für ein höheres Niveau geistiger Entwicklung.

\section{Paris - ein Ende}

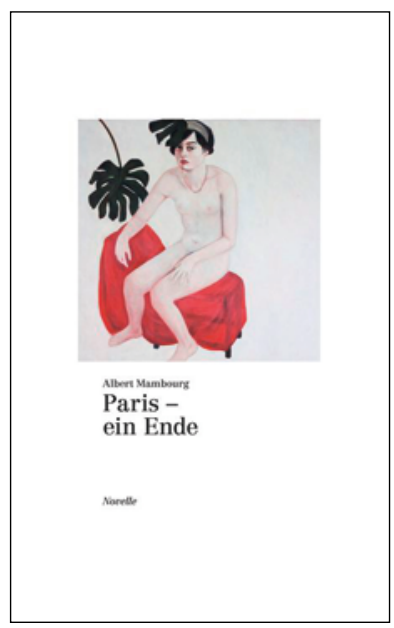

\section{Albert Mambourg \\ Paris - ein Ende}

Norderstedt: BoD Books on Demand; 2017.

60 Seiten. $12.40 \mathrm{CHF}$

ISBN 978-3-7448-1543-7

Ein Mann ist offiziell unterwegs nach Paris zum 23. Weltkongress der Alterssexualität. In Wahrheit koppelt er seine private Liebesreise mit einem steuergünstigen Kongressausflug. Eine Songline, Traumpfade, die eine Elsa umkreisen, eine Frau die ihn schon vor vielen Jah- 
ren verlassen hat. Obsessiv bleibt er in seinen Erinnerungen gefangen, immer auf den Spuren einer imaginären oder realen Elsa, der er nie begegnen wird. Sein chaotischer Weg durch Paris endet vor einer Villa in Montmartre, wo er erstmals eine Botschaft von ihr findet. Mambourg schreibt in einer poetischmonologisierenden Sprache von grotesken Umund Irrwegen, vom Leiden an einer nur subjektiv fassbaren Zeit, von der realen Welt als schlechteste aller Lösungen, der er seine irrealen Bilder entgegenhält. Es gibt nur die Fragmente durcheinanderwirbelnder Zeiten. «Paris, die Stadt, die millionenfach in Teilchen

\section{Poesie überwältigender Gefühle, denen wir, gemäss seinen Worten, folgen sollen wie den Freuden des blendenden Lichtes.}

geteilt, in alle Richtungen und in die Sekunden hinein explodiert, ohne sich eines Risikos bewusst zu sein. Ohne auch nur zu wissen, was passiert.»

\section{Dem Licht auf der Spur}

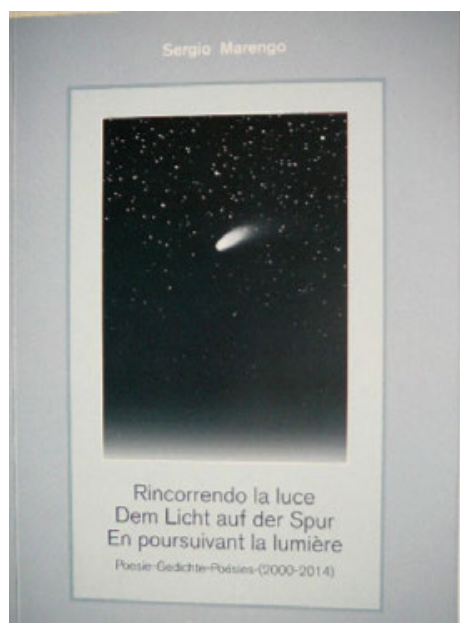

Sergio Marengo

\section{Rincorrendo la luce}

Lugano: Edizione Aline; 2014.

99 Seiten. $21 \mathrm{CHF}$.

ISBN 88-87906-24-6

Rincorrendo la luce, En pousuivant la lumière. Sergio Marengos Werk ist der mehrsprachigen Schweiz gewidmet. Themen, verteilt auf zwanzig Gedichte. Poesie überwältigender Gefühle, denen wir, gemäss seinen Worten, folgen sollen wie den Freuden des blendenden Lichtes. Der schon einmal in der Ärztezeitung vorgestellte Gedichtband ist 2014 erschienen und wurde nun

\section{Marengos Werk ist der mehrsprachigen}

Schweiz gewidmet.

im Frühjahr in Genua mit dem dritten Preis der «Serpe d'oro" 2017 für veröffentlichte Poesie ausgezeichnet. Mit den Worten der Jury: Rincorrendo la luce, opera trilingue dell'autore italo-svizzero Sergio Marengo, presenta liriche di gioiosa affermazione della positività dell'esistenza, siano esse ispirate al fascino delle donne amate o alla natura, custode anch'essa di bellezza e spiritualità. Lo stile, nell'essenzialità del verso, favorisce l'immediatezza della comunicazione. 